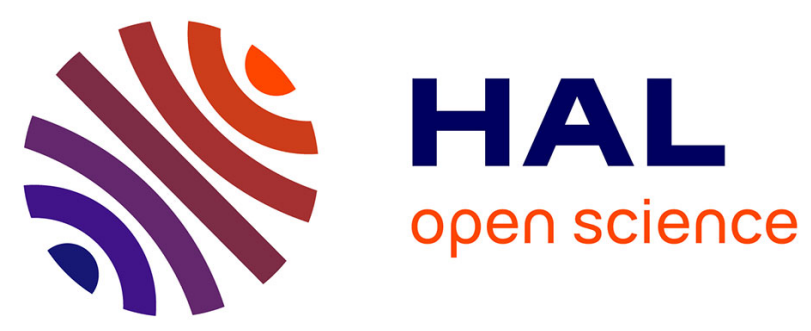

\title{
SAFEST Roadmap for Corium Experimental Research in Europe
}

\author{
C. Journeau, V. Bouyer, N. Cassiaut-Louis, P. Fouquart, P. Piluso, G. Ducros, \\ S. Gosse, A. Quaini, C. Gueneau, B. Fluhrer, et al.
}

\section{- To cite this version:}

C. Journeau, V. Bouyer, N. Cassiaut-Louis, P. Fouquart, P. Piluso, et al.. SAFEST Roadmap for Corium Experimental Research in Europe. ICONE 24 - 24th International Conference on Nuclear Engineering, Jun 2016, Charlotte, United States. cea-02442332

\section{HAL Id: cea-02442332 https://hal-cea.archives-ouvertes.fr/cea-02442332}

Submitted on 6 Apr 2020

HAL is a multi-disciplinary open access archive for the deposit and dissemination of scientific research documents, whether they are published or not. The documents may come from teaching and research institutions in France or abroad, or from public or private research centers.
L'archive ouverte pluridisciplinaire HAL, est destinée au dépôt et à la diffusion de documents scientifiques de niveau recherche, publiés ou non, émanant des établissements d'enseignement et de recherche français ou étrangers, des laboratoires publics ou privés. 


\section{ICONE24-60916}

\section{SAFEST ROADMAP FOR CORIUM EXPERIMENTAL RESEARCH IN EUROPE}

\author{
Christophe Journeau, Viviane Bouyer, \\ Nathalie Cassiaut-Louis, Pascal Fouquart \\ Pascal Piluso, Gérard Ducros \\ CEA, DEN, Cadarache \\ St Paul lez Durance, France
}

\author{
Stéphane Gossé, Christine Guéneau, \\ Andrea Quaini \\ CEA, DEN, Saclay \\ Gif sur Yvette, France
}

\author{
Beatrix Fluhrer, \\ Alexei Miassoedov, \\ Juri Stuckert, \\ Martin Steinbrück \\ KIT \\ Karlsruhe, Germany \\ Dario Manara, \\ David Bottomley \\ JRC/ITU \\ Karlsruhe, Germany
}

\author{
Sevostian Bechta, \\ Pavel Kudinov \\ $\mathrm{KTH}$ \\ Stockholm, Sweden
}

\author{
Manfred Fischer \\ Gert Langrock, \\ Holger Schmidt \\ AREVA GmbH \\ Erlangen, Germany
}

\author{
Zoltan Hozer, Attila Guba \\ MTA EK \\ Budapest, Hungary
}

\author{
Monika Kiselova, Jiri Ždarek \\ ÚJV Řež, a. s. \\ Řež, Czech Republic
}

\section{ABSTRACT}

SAFEST (Severe Accident Facilities for European Safety Targets) is a European project networking the European corium experimental laboratories with the objective to establish coordination activities, enabling the development of a common vision and research roadmaps for the next years, and of the management structure to achieve these goals. In this frame, a European roadmap on corium experimental research has been written to define research challenges to contribute to further reinforcement of Gen II and III NPP safety. It is based on the research priorities determined by SARNET SARP group as well as those from the recently formulated in the NUGENIA Roadmap for severe accidents and the recently published NUGENIA Global Vision report. It also takes into account issues identified in the analysis of the European stress tests and from the interpretation of the Fukushima accident. 19 relevant issues related to corium have been selected during these prioritization efforts. These issues have been compared to a survey of the European corium experimental facilities and corium analysis laboratories. Finally, the coherence between European infrastructures and $R \& D$ needs has been assessed and a table linking issues and infrastructures has been derived. It shows a few lacks in EU corium infrastructures, especially in the domains of core late reflooding impact on source term, Reactor Pressure Vessel failure and corium release, Spent Fuel Pool accidents, as well as the need for a large mass (100$500 \mathrm{~kg}$ ) prototypic corium facility.

\section{INTRODUCTION}

The main public safety goal for nuclear power safety is to prevent a societal disaster and huge economic loss. With appropriate site risk evaluations, plant designs and management, current Gen II and future Gen III Light Water Reactor (LWR) nuclear power plants (NPP) show high levels of robustness and very low probabilities for severe accidents. But, despite the highly efficient accident prevention measures adopted for the current Gen II and the still more demanding ones for the Gen III plants, some accident scenarios may, with a low probability, result in severe accident, as recently emphasized with the Fukushima-Daiichi accidents in Japan. This accident may eventually end-out in core melting, plant damage and dispersal of radioactive materials out of the plant 
containment, thus threatening both the public health and the environment.

This risk can be substantially decreased when state-of-the-art devices currently available for prevention and mitigation of severe accidents are implemented. Lessons from the Fukushima accidents and consequences related to Accident Management provisions from the recently completed European Nuclear Safety Regulators' (ENSREG) stress tests and other national activities will lead to further enhancement of the NPPs safety [1].

The European Sustainable Nuclear Energy Technology Platform (SNE-TP) identified Research Areas in response to the Fukushima Accident [2] and concluded that "research and development are essential tools for a better understanding of the phenomena and, thus, are necessary to derive practical indications to enhance the prevention and the mitigation of severe accidents". It also stressed that "identification of appropriate existing - and future - facilities and relevant tests" has to be considered, "even if the topic has been only marginally addressed" in the report. It also states that "Fulfilment of that objective [development of advanced methods for the analysis of severe accidents] will also require experimental research and must be implemented by a broad international co-operation at least within the EU". Finally, the recently published NUGENIA Global Vision report [3] lists issues and challenges related to corium.

The SAFEST project [4] has been launched to contribute to the establishment of an integrated pan-European laboratory for severe accident research able to address and successfully resolve the variety of the remaining issues related to the corium behavior in severe accidents. This unique consortium will be a valuable asset for the fulfilment of the severe accident $R \& D$ programs that are being set up after Fukushima and the subsequent European stress tests, addressing both national and European objectives, in collaboration with major international stakeholders. The way towards the establishment of a panEuropean laboratory will clearly depend on conclusions of roadmap activities which are a key part in the project.

The general objective of SAFEST roadmap task is to establish coordination activities, enabling the development of a common vision and research roadmaps for the next years, and of the management structure to achieve these objectives. The specific objective of this work package will be to define research challenges to contribute to further reinforcement of Gen II and III NPP safety. Moreover, safety research roadmap for next generation plant safety will be also developed taking advantage of the knowledge and expertise obtained for existing reactors as well as on specific safety characteristics of considered Gen IV designs.

In a first section, the corium-related priorities arising within several European research priority documents will be presented.
In a second section, experimental facilities will be put in correspondence with research issues. Finally, the coherence between research needs and facilities will be discussed and gaps will be listed.

\section{CORIUM RESEARCH ISSUES}

Within the European Severe Accident Research Network of excellence (SARNET) Severe Accident Research Priorities Group (SARP), research topics have been identified and ranked. This ranked list is being periodically reassessed. The latest list [5], taking into account topics emerging after the Fukushima Daiichi accident, selected the following high priority issues (In the following listings, issues related to corium have been written in bold):

1) Core and debris coolability and thermal-hydraulics within particulate debris during re-flooding

2) Corium behaviour in a lower head

3) Keeping the RPV integrity by external reactor vessel cooling (ERVC)

4) RPV vessel failure mode and the following corium release from the failed vessel, in the case of vessels with lower head penetrations such as BWRs.

5) Mixing of hydrogen in the containment (and reactor building) atmosphere, possible hydrogen combustion/detonation processes and the influence of countermeasures like Passive Autocatalytic Recombiners (PARs)or the effect of spray systems.

6) Ex-vessel fuel coolant interaction (FCI) including steam explosion (SE)

7) Molten Core Concrete Interaction (oxide-metal configurations; top-flooding)

8) Characterisation and quantification of the fission product (FP) release under oxidation conditions and in particular air ingress for High Burn-Up (HBU) and Mixed Oxide (MOX) fuel.

9) High temperature chemistry in the RCS and its impact on the source term, mainly on iodine species, as well as the chemistry of iodine in the containment and its impact on the source term.

10) Fuel Assembly (FA) behaviour in spent fuel pool severe accident scenarios

11) Development and qualification of specific instrumentation for $\mathrm{SA}$ conditions.

The following medium priority issues have also been determined:

a. Hydrogen generation during re-flooding of strongly degraded cores

b. Integrity of RCS, especially integrity of Steam Generator tubes in High Pressure scenarios

c. Direct Containment Heating (DCH)

d. Long term loss of heat removal from wetwell in a BWR

e. Dry Molten Core Concrete Interaction (with single oxidic phase) 
f. Dynamic and static behaviour of containment, crack formation

g. Core re-flooding impact on source term during late phases of core degradation (with highly degraded core loss of geometry)

h. Effect of impurities in water on corium behaviour

i. Data(bases) on corium thermodynamic and thermophysical properties.

Recently, NUGENIA Global Vision Report [3] listed the following main challenges relative to corium research and development:

- Hydrogen generation during melt relocation and flooding;

- Reflooding of debris beds;

- Corium coolability in lower head and integrity of RPV due to external vessel cooling;

- Fuel Coolant Interaction including steam explosion and particulate formation;

- Direct Containment Heating scaling effects and hydrogen combustion during DCH, in particular for BWR;

- Molten Core Concrete Interaction (MCCI) and corium catchers;

- Ex-vessel corium coolability by top flooding;

- Ex-Vessel corium catcher;

- Ex-Vessel debris bed formation and coolability;

- Spent fuel pool scenarios in case of loss of the cooling system;

- Re-criticality in SA conditions;

- Instrumentation for SA diagnosis and management;

- Development of new accident tolerant fuels (ATF).

Finally Bruna et al. [2] stated that, "on longer term - in several years - the outcomes of the future expertise acquired on the four reactors and fuel pools of Fukushima Daiichi site will be very valuable for the qualification and validation of results of the proposed $R \& D$ tasks". Indeed, material analyses of Fukushima Daiichi corium samples will be an important source of phenomenological insights on severe accident processes, as it used to be for TMI2 samples, several of which have been analysed in EU labs. We have thus added a specific issue related to the analyses of Fukushima Daiichi corium samples and their development/qualification using prototypic corium samples from EU facilities.

From those analyses, it appears that 19 corium-related issues have been recognized as having high (in bold) or medium priority. The remainder of this paper will be dedicated to the experimental R\&D concerning those priority issues:

1) Core and debris coolability and thermal-hydraulics within particulate debris during re-flooding

2) Hydrogen generation during re-flooding of strongly degraded cores
3) Core re-flooding impact on source term during late phases of core degradation (with highly degraded core loss of geometry)

4) Corium behaviour in a lower head

5) Keeping the RPV integrity by external reactor vessel cooling (ERVC)

6) RPV vessel failure mode and the following corium release from the failed vessel, in the case of vessels with lower head penetrations such as BWRs

7) Ex-vessel fuel coolant interaction (FCI) including steam explosion (SE)

8) Direct Containment Heating (DCH)

9) Dry Molten Core Concrete Interaction (with single oxidic phase)

10) Molten Core Concrete Interaction (oxide-metal configurations; top-flooding; liquid source term)

11) Ex-vessel Core catchers

12) Debris formation and Coolability (in and ex-vessel)

13) Effect of impurities in water on corium behaviour

14) Recriticality in severe accident conditions

15) Spent Fuel Pool scenarios in case of loss of cooling system

16) Development and qualification of specific instrumentation for $\mathrm{SA}$ conditions

17) Databases on corium thermodynamic and thermophysical properties

18) Accident Tolerant Fuels

19) Analyses of Fukushima Daiichi corium samples

\section{Examples of Issues}

As it is not possible to describe in detail all the 19 issues in this paper, two of them are detailed as examples.

Issue 4: Corium Behaviour at Lower Head. It is generally assumed that the lower head is filled with water when corium enters this area from the core zone. It also seems likely that this corium contains a substantial fraction (between $25 \%$ $80 \%$ ) of unoxidized Zircaloy (cladding material), which can then be oxidized.

There are two main risks when corium relocates to the lower head. One is that, when hot corium comes into contact with residual water, the steam produced will cause a pressure spike, or even an in-vessel steam explosion. The other risk is that upon contact with corium, the vessel will undergo heat fluxes, which may be of considerable magnitude locally, potentially resulting in vessel rupture. For such scenarios, safety studies should be able to determine the likelihood of in-vessel corium retention and the conditions under which vessel rupture would occur (timescale, location, characteristics of the corium transferred into the containment).

Steady state behavior of debris and of molten pools in the lower head has been investigated in several experimental 
studies. For instance, regarding experiments in large scale geometry using water as simulant material for corium, COPO II and BALI experiments performed in 2D slice geometry showed clearly higher heat transfer coefficients (20-30\%) for the side and bottom boundaries than those in the 3D ACOPO experiments, while the upward heat transfer coefficients were only slightly higher. In LIVE experiments with cooling upper surface and crust formation on the boundary higher upward heat (30-50\%) fluxes were determined, as compared to the tests with water and no crust. This implies a different top to downward split, which in the reactor case would be important e.g. for the amount of heat transferred to an overlying metallic layer and thus the strength of the focusing effect. Clear conclusion could not yet be drawn. Moreover, the database for the transient processes during core melting, melt relocation and accumulation is still very limited. For the melt released into the lower head of the vessel, there is a lack of information about e.g. transient heat fluxes through the vessel wall, crust formation, stability and re-melting in 3D geometry.

Another yet unresolved question is related to the existence of mushy layers or sharp interfacial boundaries along crust boundaries in the case of non-eutectic melt. Different approaches exist, either assuming a mushy layer with larger temperature differences between melt bulk and pool boundary, but smaller heat transfer coefficients due to increased viscosity caused by solid fractions, or sharp liquid/solid boundaries with the surface temperature at liquidus temperature, thus smaller temperature differences but larger heat transfer coefficients. The experimental and theoretical studies performed up to now did not yield a decision yet.

Thus there is a critical need to predict the changes corium will undergo, from its relocation towards the lower head to formation of the molten pool or corium cooling. The main phenomena, which can govern these changes, are - corium jet fragmentation and debris formation; - debris bed dry-out and reflooding possibilities; - formation of molten pool; - natural convection in the molten pool; - focusing effect; - corium oxidation including $\mathrm{H}_{2}$ production; - metal/oxide stratification in the molten pool; - dissolution of reactor vessel steel at submelting point temperatures.

Issue 19: Analyses of Fukushima Daiichi corium samples. The European nuclear research institutes are interested in supporting the Japanese initiative to research the accident both with experimental research and advice. This will gain practical experience in handling and understanding severe accidents in reactors and so gaining knowledge and improving design to avoid them in the future.

From the above résumé, that can be seen that Fukushima fuel debris have a number of features that make them of great importance for investigation and understanding of severe accident mechanisms. This has already been discussed by the Severe Accident Research Priority group (SARP) of SARNET [5].

Firstly Fukushima Daiichi is a BWR reactor site, so that there is far more $\mathrm{B}_{4} \mathrm{C}$ present in the reactor inventories compared to the LWR design (eg. TMI-2). However it remained under steam for most of the accident so that the $\mathrm{B}_{4} \mathrm{C}$ will not have been oxidised, thus actinide boride and carbide formation is likely. This has also raised concerns in Japan that these hard materials could be particularly difficult to break up and remove during dismantling.

Secondly it was obliged to use untreated/unfiltered sea-water for maintenance of the reactor vessel water levels and so large amounts of chlorides, sulphates particularly of sodium, calcium and magnesium have entered a previously clean system. JAEA research has shown that despite the presence of $\mathrm{Cl}$ and $\mathrm{Na}, \mathrm{CaSO}_{4}$ is the main deposit resulting from sea-water evaporation and which considerably alters the stability of certain actinides; other thermodynamic calculations show how chloride could increase Cs release.

In summary the full investigation of the Fukushima samples retrieved from the damaged reactor basements are crucial to extracting the maximum amount of knowledge and understanding from this accident. This is particularly relevant for the MCCI sites where the final forms of the material and fuel debris are expected to be retrieved from. These will provide real irradiated data on corium forms and formation and will help verify the improved modelling necessary to reproduce these series of phenomena. Also Fukushima fuel debris/corium will provide essential data for the performances expected for a basemat to retain corium in a BWR reactor or that restricts the corium advance and penetration to a known rate and location. Here the presence of chloride in the melt may substantially change the aggressiveness of the corium melt.

This is an issue of international importance and so the SAFEST and other EC-supported projects in the severe accident field should also contribute as much as possible to advance the understanding of severe accidents from the events at Fukushima Daiichi.

In preparation of this important work program, corium facilities can be useful to provide prototypes of the corium which is expected to be found at various locations of the damaged plants. These prototypes can be used to test debris sampling/cutting techniques as well as debris chemical analysis techniques and processing methods with lower radiation doses and before actual Fukushima debris samples are available. 


\section{CORIUM FACILITIES}

Experimental research is an important part of the corium R\&D. Due to the many coupled phenomena, the poor current knowledge on corium thermodynamic and thermophysical properties, it is necessary to perform experiments during severe accident research programs. Several experimental facilities exist both within and outside SAFEST consortium. In this chapter, the relevant facilities will be presented and be linked to the relevant issues that may be studied with them. This analysis is clearly focused on EU facilities but also consider non-European facilities having ties to EU research organizations.

The following 36 facilities (or platforms) have been reviewed:

1. QUENCH [7] at KIT, devoted to issues 1, 2, 12, 13 and 18 ;

2. CODEX [8] at MTA EK, devoted to issues 1, 2, 13, 15 and 18;

3. DEFOR [9] at KTH, devoted to issues 12 and 13;

4. JEBRA at KTH, devoted to issues 8,12,14;

5. PRELUDE [10] at IRSN, devoted to issues 1, 12 and 13 ;

6. PEARL [11] at IRSN devoted to issues $1,12,13$;

7. DEBRIS [12] at IKE devoted to issues 1, 12, 13;

8. COOLOCE at VTT, devoted to issues 1, 12, 13;

9. POMECO at $\mathrm{KTH}$, devoted to issue 12;

10. LIVE [14] at KIT, devoted to issues 6 and 12;

11. RASPLAV-3[15] at NITI devoted to issues 4 and 14;

12. VITI [16] at CEA devoted to issues $4,9,10,13,17$ and 18 ;

13. RESCUE [17] at CEA, devoted to issue 5;

14. CERES [18] at MTA EK devoted to issue 5;

15. IVR facility [19] at CNPRI devoted to issue 5;

16. IVR facility under construction at UJV devoted to issue 5 ;

17. REPEC [20] at SJTU devoted to issue 5;

18. KROTOS [16] at CEA, doted to issues 7,12 and 17;

19. PLINIUS-2 [21] future CEA multi-purpose facility devoted to issues $4,7,9,10,11,12,13,14,16,18,19$;

20. MISTEE at KTH for issues 8 and 13;

21. SES at KTH for issues 7, 11 and 13;

22. DISCO [22] at KIT for issue 7 and 8 ;

23. VULCANO [16] at CEA for issues 4, 9,10, 11, 16 and 19 ;

24. SICOPS at AREVA for issues 9, 10 and 11;

25. HECLA at VTT for issue 10;

26. CCI and SSWICS [24] at ANL for issues 9 and 10;

27. MOCKA [25] at KIT for issues 10 and 11;

28. CLARA [26] at CEA for issue 9 and 10;

29. BENSON at AREVA for issue 11;

30. COMETA [27] at UJV for issue 9, 10, 11, 13 and 17;

31. ATTILHA at CEA for issue 4, 9 and 17;

32. FLF [28] at ITU for issues 13, 14, 15, 17, 19;
33. ITU thermodynamic property measurement facilities for issues 13,14, 15, 17 and 19;

34. LECA-STAR at CEA for issue 19;

35. NUCLAB at CEA for issue 19;

36. LIPC analysis laboratory at CEA for issue 17 .

\section{Examples of Facilities}

As for issues, two facilities are described as examples.

QUENCH Facility. The main component of the QUENCH test facility [7] is the test section (Fig. 1) with the test bundle. The facility can be operated in two modes: a forced-convection mode (typical for most QUENCH experiments) and a boil-off mode. In forced-convection mode the superheated steam from the steam generator and superheater together with argon as a carrier gas for off-gas measurements enter the test bundle at the bottom.

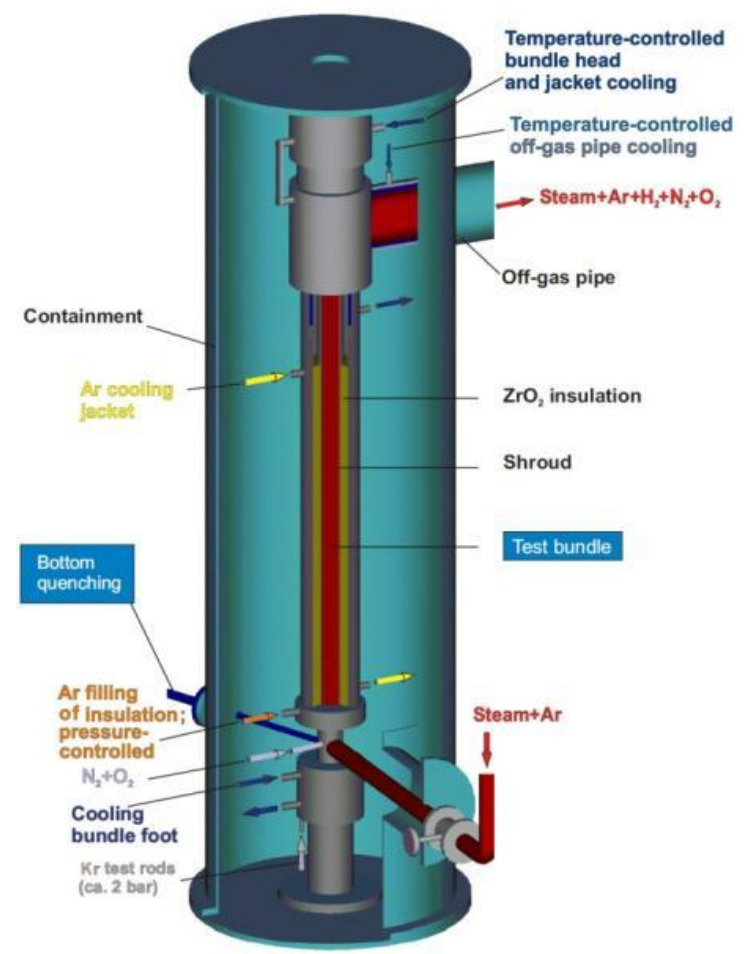

Fig. 1: QUENCH Facility: Containment and test section

The test bundle is approximately $2.5 \mathrm{~m}$ long and is made up of 21 (Fig. 2),24 or 31 fuel rod simulators depending on cladding size and bundle geometry (quadratic or hexagonal). The fuel rod simulators with $\mathrm{Zr}$-alloy claddings are held in position by five grid spacers. The rods can be heated or unheated. Heating is electric by tungsten heaters installed in the rod center. Electrodes of molybdenum and copper are connected to the tungsten heaters at one end and to the cables leading to the DC electrical power supply at the other end. All test rods can be filled with $\mathrm{Kr}$ or $\mathrm{He}$ at a pressure between 0.2 and 5.5 $\mathrm{MPa}$ absolute. The rods are connected to a controlled feeding system that compensated minor gas losses and allowed 
observation of the first cladding failure as well as a failure progression.

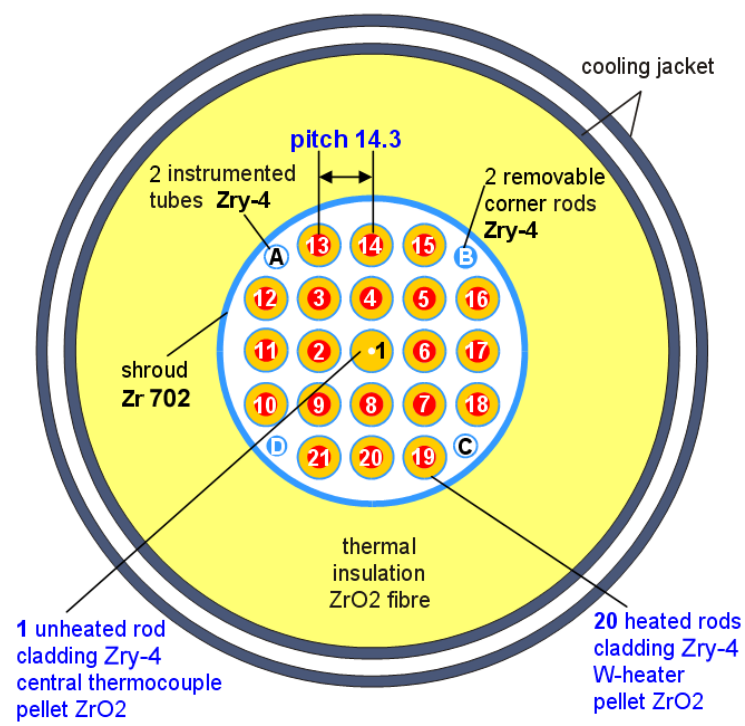

Fig. 2: Example of QUENCH bundle cross-section

The test section has separate inlets at the bottom to inject water for reflood (bottom quenching) and synthetic air $\left(80 \% \mathrm{~N}_{2}\right.$ $+20 \% \mathrm{O}_{2}$ ) in case of air ingress test. The argon, the steam and gases not consumed, and the hydrogen produced in the zirconium-steam reaction flow from the bundle outlet at the top through a water-cooled off-gas pipe to the condenser where the steam is separated from the non-condensable gases. The water cooling circuits for bundle head and off-gas pipe are temperature-controlled to guarantee that the steam/gas temperature is high enough so that condensation at the test section outlet and inside the off-gas pipe is avoided.

The QUENCH facility is mainly devoted to the study of issues 1 (Core and debris coolability) and 2 (Hydrogen generation during late debris reflooding). It can also contribute to the testing of candidate Accident Tolerant Fuels (issue 18) and to study the effect of water impurities during core quenching (issue 13). A QUENCH-debris configuration is also available, which can be used within issue 12 (debris coolability).

KROTOS Facility. The KROTOS facility [16] is dedicated to FCI (water as coolant prototypic corium as fuel) understanding. KROTOS consists of four main parts (see Fig. 3 ): a radiation furnace (1), the release tube (3), the test section (5) and the X-Ray radioscopy system.

The radiative furnace is a controlled atmosphere vessel consisting of a cylindrical tungsten heater element, which encloses the crucible containing the melt material (1.5 liter maximum). After having reached the desired melt temperature, the crucible is released thanks to a rapid-acting ball valve. It falls down in the $4 \mathrm{~m}$ long release tube until the impact on a puncher located at the top of the test section permitting the corium to flow down to the test section. The test section is a pressure vessel with a test tube inside $(200 \mathrm{~mm}$ inner diameter, $\sim 1.15 \mathrm{~m}$ height), both are made of Fortal, a low-density aluminium alloy. There are some different designs depending on the studied phenomena: the bottom of the test section enables to study steam explosion or to characterize mixing (melt and void distribution) and debris bed. The top of the furnace can be modified to perform aerosol tests.

KROTOS can thus contribute to R\&D on issues 7 (Fuel Coolant Interaction), 12 (Debris formation) and 17 (Thermodynamic properties of corium and aerosols).

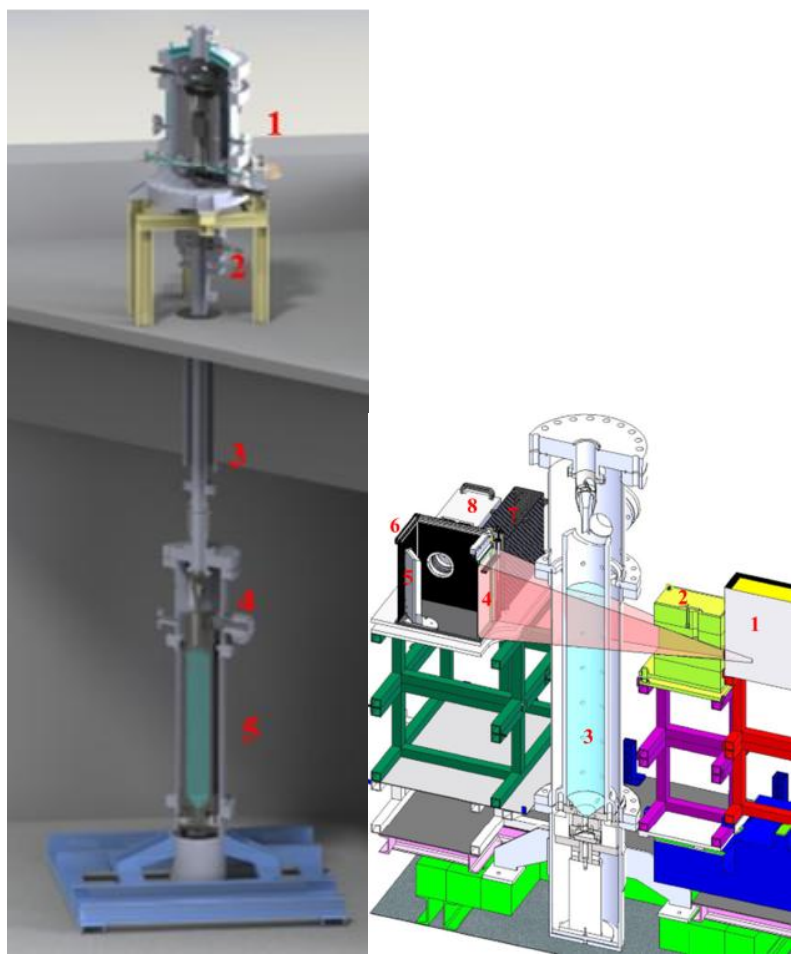

Fig. 3: Left: 3D drawing of KROTOS facility. radiative furnace (1), rapid-acting ball valve (2), release tube (3), puncher and release cone (4), test section (5). Right: X-ray radioscopy system

\section{SYNTHESIS}

A detailed analysis of the issues and facilities indicated that experimental capabilities exist to conduct experimental research on almost all of the priority issues listed in the European roadmap documents.

Nevertheless, there is a need of a new facility to address the core late re-flooding impact on Source Term, in relation to Fukushima feedback. This facility would be devoted to elaborate leaching rate data which are missing, from melted and re-solidified irradiated fuel debris. Debris samples would be post-test samples coming from heated irradiated fuels under conditions simulating a severe accident (VEGA, 
VERCORS/VERDON, PHEBUS-FP ...) and/or similar spent fuel samples melted with concrete. These samples would be leached in hot cells for an immersion period from a few months to a year in different water solutions: deionized water, sea water, water and boric acid, hydrazine ...

Leaching rates of actinides $(\mathrm{U}, \mathrm{Pu})$ and low volatile fission products, in particular Sr, are of the highest concern. In a first stage, prototypic corium samples with natural-isotope prototypes of fission products could be used.

Although issue 6 on RPV failure mode and corium release has been judged to be of high priority [5] especially in the case of vessels with lower head penetrations such as BWRs, there is currently no experimental facility to study this complicated issue. Efforts are encouraged on this topic.

The last need is related to a large scale prototypic corium facility. Except for CCI facility (which is devoted to MCCI and cannot heat melts with significant content of steel) using about $1 \%$ of the core inventory, the European prototypic corium facilities are limited to a few $10^{-4}$ th of the corium inventory (few tens of kilograms). CEA PLINIUS2 facility is intended to fill this gap.

In summary, the 16 facilities from the SAFEST consortium are available to tackle most of the issues relative to corium behaviour. Some other European facilities as well as nonEuropean facilities having links to European organizations complete this map of corium experimental capabilities. There are still needs for new experimental capabilities on the core late re-flooding impact on Source Term and on RPV failure mode and corium release with lower head penetrations, as well as on a European large scale multi-purpose prototypic corium facility.

\section{ACKNOWLEDGMENTS}

The SAFEST project is funded by the EURATOM 7th Framework Programme under grant agreement $n^{\circ} 604771$.

\section{REFERENCES}

[1] Van Dorsselaere, J.P. et al., "Technical Area 2 - Severe Accidents", In : NUGENIA Roadmaps, K. Ben Ouagrhem, ed., NUGENIA, 2013, http://www.nugenia.org

[2] Bruna, G.. et al., "Identification of Research Areas in response to the Fukushima Accident", SNE-TP Report, 2013, http://www.snetp.eu

[3] NUGENIA, "Global Vision report, Nuclear Gen II and III Association", Brussels, April 2015, http://www.nugenia.org

[4] Miassoedev, A. et al., "Severe Accident Facilities for European Safety Targets. The SAFEST Project", Proc. ERMSAR, Marseille, 2015, http://www.sar-net.eu
[5] Klein-Hessling, W. et al., 2014, "Conclusions on severe accident research priorities”, Ann. Nucl. Ener., 74, pp. 411.

[6] Suzuki, A., Sato K., Terei, T., 2014, 'Thermodynamic calculation on possible chemical forms of released fission products from failed fuel rod in severe accident conditions', 2nd Asian Nuclear Fuel Cycle Conference (ANFC2014), 18-, Tohoku University, Sendai, Miyagi, Japan

[7] Steinbrück, M., Grosse, M., Sepold, L., Stuckert, J., 2010, "Synopsis and outcome of the QUENCH experimental programme", Nucl. Eng. Des., 240, pp.1714-1727.

[8] Hozer, Z. et al. , 2010, "Quenching of high temperature VVER fuel after long term oxidation in hydrogen rich steam”, Nucl. Eng. Des., 37, pp. 71-82.

[9] Karbojian, A., Ma, W., Kudinov, P., Dinh, T.N., 2009, “A scoping study of debris formation”, Nucl. Eng. Des., 239, pp.1653-1659.

[10] Repetto, G.., Garcin, T., Eymery, S., Fichot, F., 2013, "Experimental program on debris reflooding (PEARL) Results on PRELUDE facility", Nucl. Eng. Des., 264, pp. 176-186.

[11] Chikhi, N., Garcin, T., Foubert, F., March, P., Fichot, F. "First experimental results of large-scale debris bed reflood tests in the PEARL facility", Proc. NURETH-16, Chicago, 2015.

[12] Starflinger, J. et al., 2015, "Recent numerical simulations and experiments on coolability of debris beds during severe accidents of light water reactors", Nucl. Eng. Des., 294, pp. 153-160.

[13] Takasuo, E., Holmström, S., Kinnunen, T., Pankakoski, P.H., 2012, "The COOLOCE experiments investigating the dryout power in debris beds of heap-like and cylindrical geometries", Nucl. Eng. Des., 250, pp. 687-700.

[14] Gaus-Liu, X., Miassoedov, A., Cron, T., Wenz, T. , 2010, "In-vessel melt pool coolability test - Description and results of LIVE experiments", Nuclear Engineering and Design 240, pp. 3898-3903.

[15] Granovsky, V.S. et al., 2014, “Oxidation effect on steel corrosion and thermal loads during corium melt in-vessel retention", Nucl. Eng. Des., 278, pp. 310-316.

[16] Bouyer, V., Cassiaut-Louis, N., Fouquart, P. Piluso, P., 2015, "PLINIUS Prototypic Corium Platform: Major Results and Future Works", Proc. NURETH, Chicago.

[17] Guénadou, D., Verloo, E., 2012, "Presentation of the RESCUE facilities for in Vessel Corium Retention studies: Toolbox for improving the modelling", Proc. Nuclear Energy New Europe, Ljubjana, Slovenia.

[18]Ézsöl, G. et al., 2010, "Modelling of External Cooling for In-Vessel Corium Retention in VVER-440/213 Type Nuclear Power Plants", Proc. 18th International Conference on Nuclear Engineering, Xi'an, China.

[19] Chen X., Zhang S., Lin J., Zhang H., 2010, “The Analytical and Experimental Research of In-Vessel Corium Retention 
in CPR1000", 18th International Conference on Nuclear Engineering, Xi'an, China.

[20] Cheng X., Yang Y.H., Ouyang Y., Miao H.X., 2009, "Role of Passive Safety Systems in Chinese Nuclear Power Development", Sci. Technol. Nucl. Install., 573026.

[21] Journeau C. et al. , 2014, "PLINIUS-2: A New Versatile Platform for Severe Accident Assessments", Proc. NUTHOS-10, Okinawa, Japan.

[22] Meyer L. et al., 2011, "Melt Dispersion and Direct Containment Heating (DCH) Experiments for Konvoi Reactors”, KIT Scientific Reports 7567, Karlsruhe Institut für Technologie (KIT), Karlsruhe, Germany.

[23] T. Sevón et al., , 2010, "HECLA experiments on interaction between metallic melt and hematite-containing concrete", Nucl. Eng. Des., 240, pp. 3586-3593.

[24] Farmer, M. T. et al., 2007, "A Summary of Findings from the Melt Coolability and Concrete Interaction (MCCI) Program," Proceedings ICAPP '07, Paper 7544, Nice, France.
[25]Foit, J.J. et al., 2014, "Experiments on MCCI with oxide and steel", Annals of Nuclear Energy 74(2014), pp. 100109.

[26] Amizic, M., Guyez, E., Seiler, J.M., 2012, "Experimental Investigation on heat transfer for two-phase flow under natural convection. First CLARA test results", Proceedings of ICONE20, Anaheim, USA.

[27]Petrov, Yu.B. et al., 2009, "Phase Equilibria during crystallization of melts of the Uranium Oxide- Iron Oxide System in Air", Glass Phys. Chem., 35, pp. 298-307.

[28] Manara, D. et al., 2005, "Melting of stoichiometric and hyperstoichiometric uranium dioxide", J. Nucl. Mater., 342, pp. 148-163. 